\title{
Progress in breeding sheep for resistance to ryegrass staggers
}

\author{
C. A. MORRIS and N. C. AMYES \\ AgResearch, Ruakura Research Centre, PB 3123, Hamilton, New Zealand. \\ chris.morris@agresearch.co.nz
}

\begin{abstract}
Ryegrass Staggers (RGS) is predominantly a summer/autumn metabolic disorder of ruminants, caused by ingestion of the toxin lolitrem B. The toxin is produced by an endophyte (Neotyphodium lolii) found in perennial ryegrass (Lolium perenne). In clinical cases of RGS, animals experience neuromuscular uncoordination when under stress, e.g. when mustered by sheep dogs. Experiments with a standardised RGS scoring system show that resistance/susceptibility in sheep has a moderate/high heritability $(0.37 \pm 0.05)$. An AgResearch flock was established in 1993, with two lines bred for resistance (R) or susceptibility (S) to RGS. Annually, lambs are scored for susceptibility, when both lines graze together on high endophyte pastures, and are mustered by sheep dogs. In 2005 and 2006, 2\% and $6.5 \%$ of R-line lambs, respectively, showed clinical staggers, compared with $94 \%$ and $91 \%$ of S-line lambs $(\mathrm{P}<0.001)$. Other results of genetic progress are also described.
\end{abstract}

Keywords: sheep; breeding; resistance; ryegrass staggers, lolitrem B

\section{Introduction}

Ryegrass Staggers (RGS) is predominantly a summer/autumn metabolic disorder of ruminants, caused by ingestion of the toxin lolitrem B. The toxin is produced by an endophyte (Neotyphodium lolii) found in perennial ryegrass (Lolium perenne). In clinical cases of RGS, animals experience neuromuscular uncoordination when under stress, e.g. when mustered by sheep dogs. RGS is of welfare concern, and it is costly to farmers because it severely compromises grazing management.

Much is understood about the perennial ryegrass/endophyte association, and methods have been developed for reducing or preventing lolitrem B production whilst still providing the host plant with the means to continue producing toxins against insects (Easton \& Tapper 2005). However, much less is known about effects of the toxin on livestock, and on animal variation

Figure 1 Response to genetic selection for resistance or susceptibility to ryegrass staggers in two lines of sheep, by year of birth, 1993-2006. The Breeding Value (BV) for resistance to RGS (standardised RGS score) is defined as the 'value of an animal as a parent'; signs are reversed in the graph so that resistance is shown with a positive sign and susceptibility with a negative sign.

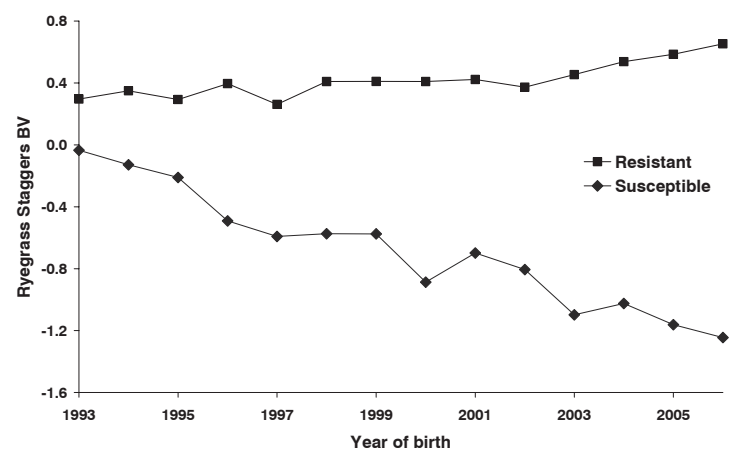

in resisting the toxin. A paper presented to the New Zealand Grassland Association by Hewett (1983) showed sire differences in RGS susceptibility on his North Canterbury sheep farm. Follow-up breeding work (Campbell 1986), with 19 sire groups and 5 lamb progeny per sire, recorded using Keogh's (1973) scoring system, provided preliminary evidence to suggest that differences in resistance/susceptibility were inherited (heritability $\left(h^{2}\right)$ estimate $=0.47 \pm 0.30$ ). The findings were considered further by Neale Towers and the senior author (CAM), who progenytested another 25 lamb-sire groups (with a combined total of 2307 progeny, including scores on ewes and the ewes' sires) for resistance or susceptibility to RGS over 5 years up to 1992 (Morris et al. 1995a). This culminated in 1993 in the establishment by AgResearch of two breeding lines of sheep selected for resistance (R) or susceptibility (S) to RGS, and the present paper describes some of the results from these breeding lines.

\section{Methods}

\section{Establishment and subsequent selection of sheep lines}

In 1993, top-ranked rams and ewes (for the R line) and bottomranked rams and ewes (for the $\mathrm{S}$ line) were identified from the progeny tests for RGS susceptibility already completed. R x R matings and S x S matings were then set up at Ruakura from 1993 onwards, with about 100 breeding ewes per line. Animals were predominantly Romney x Coopworth crosses.

Using an RGS scoring system on lambs each year (described below), a response to the original screening was achieved in the 1993 lamb crop (Fig. 1). Most of the subsequent withinline responses until 2002 were in the S line (also Fig. 1). This was because the perennial ryegrass-dominant pastures to which we had access at Ruakura did not provide sufficiently severe natural pasture challenges to rank R-line rams accurately for susceptibility. The 2001-born lambs were transferred from Ruakura to AgResearch Lincoln, and RGS scoring of lambs has continued since then at Lincoln where more severe RGS challenges have been experienced at pasture.

\section{Scores}

With large numbers of lambs to score regularly, and limited labour availability, we modified Keogh's (1973) 0-5 system in 1988/89 initially to a less labour-intensive RGS scoring procedure with a binomial score (i.e. whether an animal had shown clinical RGS with inability to walk (scores 4 or 5 on the Keogh scale), at least once by the end of the season, when under the stress of being mustered by sheep dogs). Since 2001, the scoring system was improved to take account of increasing severity of challenge over the grazing season, as follows: tag-numbers and a date were recorded for any animals showing clinical RGS on the first scoring occasion; clinically affected animals from both lines were removed from the grazing group. The cycle was repeated on the remainder of animals when challenged again a few days later. Removing clinical cases from the grazing group was required for welfare reasons. Also, a high 'between-animal repeatability' over time would be expected if clinical cases were not removed from the group, because of toxin accumulation in the body over time.

At the end of the season (consisting of $n$ scoring dates, maximum $=10$ ), clinical cases on the first scoring day were scored as $n$, those 
Figure 2 Example showing the time course of recorded cases of clinical ryegrass staggers in lambs born in 2005 from the genetically resistant and susceptible lines.

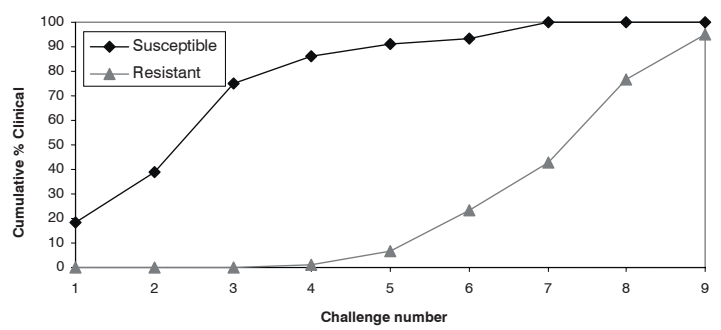

on the next day were scored as $(n-1)$, those on the last day were scored as ' 1 ', and those not clinically affected up to the last scoring day were scored as ' 0 '. Because of variable toxin challenge over time, the intervals between adjacent dates where new clinical cases occurred were not uniform, so we avoided using date (or number of grazing days) as part of the RGS score. An example is given in Figure 2 showing the time course of recorded cases of clinical RGS in lambs from the two selection lines, with a 0-9 scale from 9 scoring days in that year. In some years there was also the opportunity to score yearlings and/or ewes for RGS, and their data were included as separate contemporary groups (see below).

\section{Analyses}

A contemporary group was defined as the year-of-scoring x stockclass of animal (ram lamb, ewe lamb, breeding ewe, etc.). All coded data for RGS score were standardised within contemporary groups each year, to reflect the difference in ranges of scores collected in different years (varying numbers and severities of challenge). Accumulated standardised data (named as 'standardised RGS score') were analysed each year to rank all the new season's lambs, and to update the scores on parents (both sires and dams). The analysis used a restricted maximum likelihood procedure (Gilmour 1997), including a full pedigree relationship matrix, with a fixed effect for contemporary group. Effectively, all animals were compared with contemporaries from the same grazing group, with results pooled over contemporary groups. Analysis of the standardised RGS scores provided a Breeding Value (BV) for RGS resistance for each animal, where the $\mathrm{BV}$ is defined as the value of an animal as a parent. The analysis also yielded a moderate/ high heritability of $0.37 \pm 0.05$ (i.e. it is a trait that will respond to selection), and the phenotypic standard deviation $\left(\sigma_{\mathrm{p}}\right)$ before standardisation was 0.79 RGS score units.

\section{Results and Discussion}

\section{Genetic response estimates}

From the above analysis of data through to the 2006 lamb crop, a divergence of about $2.4 \sigma_{\mathrm{P}}$ was achieved between the lines in 13 years (Fig. 1). About 28\% of the selection response to 2006 was in the $\mathrm{R}$ line, and $72 \%$ in the $\mathrm{S}$ line. Larger annual responses have been recorded in the $\mathrm{R}$ line since 2002, as a result of the greater RGS challenge now being experienced. Over the 4 years 20022006 , the annual genetic response in the R line was $76 \%$ of that in the $\mathrm{S}$ line. In the 2005 and 2006 scoring seasons, $2 \%$ and $6.5 \%$ of R-line lambs, respectively, showed clinical staggers, compared with $94 \%$ and $91 \%$ of S-line lambs, respectively $(\mathrm{P}<0.001)$.

Rates of response to selection in the $\mathrm{S}$ line are broadly consistent with what would be expected for a multi-genic trait, but the response could also be explained by a major gene segregating. Therefore, all recent selection-line animals and the back-cross and out-cross lambs derived in a related study (Amyes et al. 2002), have had DNA samples stored for future molecular analysis.

Resistance/susceptibility to facial eczema is also an inherited trait in sheep (Morris et al. $1995 \mathrm{~b} ; \mathrm{h}^{2}=0.45 \pm 0.05$ ), and work at Ruakura, scoring both RGS and facial eczema resistances on the same animals, has shown a genetic correlation of 0.31 between resistance to RGS and to facial eczema (Morris et al. 1995a). Therefore, at least some of the genes for detoxification are in common for these two metabolic conditions, despite the toxins not being closely related chemically.

\section{Possible industry applications}

The scoring system currently in use is still labour-intensive, and would probably be onerous for ram breeders. They would have to feed their animals on pastures containing high levels of lolitrem B (to rank the more resistant rams), which typically would lead to sub-optimal liveweight gains in autumn. However, with the data in Figure 1 collected under research conditions, we have demonstrated that an animal breeding solution should be biologically feasible in the industry. Finding the gene(s) or DNA markers for RGS resistance in sheep would solve the labour-intensive constraint associated with scoring animals for RGS resistance, and would allow ram-breeders or commercial farmers to use marker-assisted selection for RGS resistance, especially for the rams required in the flock.

Although perennial ryegrass strains are now available carrying endophyte which does not produce lolitrem $\mathrm{B}$, the re-seeding rate of these strains over New Zealand is slow (about $3 \%$ of ryegrass pastures re-seeded per annum). At this rate it will be many years before re-seeding could be complete on the land where re-sowing is possible, and there are many of the less profitable sheep and beef farms where it may not be economic or practical to re-seed. An alternative animal-genetic solution might be used in future by those farmers who are unable to re-seed, which was described by Hewett (1983) as the 'inflation-proof long-term solution'.

\section{REFERENCES}

Amyes, N.C.; Towers, N.R.; Morris, C.A. 2002. Ryegrass staggers: genetics accounts for a six-fold difference in susceptibility between selection lines of lambs at Ruakura. Proceedings of the New Zealand Society of Animal Production 62: 191-194.

Campbell, A.G. 1986. Selection strategies for animal disease resistance. New Zealand Agricultural Science 20: 169-171.

Easton, H.S.; Tapper, B.A. 2005. Neotyphodium research and application in New Zealand. pp. 35-42. In: Neotyphodium in Cool-Season Grasses. Eds. Roberts, C.A.; West, C.P. and Spiers, D.E., Blackwell Publishing, Oxford, U.K.,

Gilmour, A.R. 1997. ASREML for testing fixed effects and estimating multiple trait variance components. Proceedings of the Association for the Advancement of Animal Breeding and Genetics 12: 386-390.

Hewett, R.L. 1983. Breeding for resistance to ryegrass staggers, the inflation-proof long-term solution? Proceedings of the New Zealand Grassland Association 14: 244-247.

Keogh, R.G. 1973. Induction and prevention of ryegrass staggers in grazing sheep. New Zealand Journal of Experimental Agriculture 1: 55-57.

Morris, C.A.; Towers, N.R.; Wheeler, M.; Amyes, N.C. 1995a. Anote on the genetics of resistance or susceptibility to ryegrass staggers in sheep. New Zealand Journal of Agricultural Research 38: 367-371.

Morris, C.A.; Towers, N.R.; Wheeler, M.; Wesselink, C. 1995b. Selection for or against facial eczema susceptibility in Romney sheep, as monitored by serum concentrations of a liver enzyme. New Zealand Journal of Agricultural Research 38: 211-219. 